University of Nebraska - Lincoln

DigitalCommons@University of Nebraska - Lincoln

2006

Impacts of Irrigation on 20th Century Temperature in the Northern Great Plains

Rezaul Mahmood

University of Nebraska - Lincoln

Follow this and additional works at: https://digitalcommons.unl.edu/natrespapers

Part of the Natural Resources and Conservation Commons, Natural Resources Management and Policy Commons, and the Other Environmental Sciences Commons

Mahmood, Rezaul, "Impacts of Irrigation on 20th Century Temperature in the Northern Great Plains" (2006). Papers in Natural Resources. 1274.

https://digitalcommons.unl.edu/natrespapers/1274

This Article is brought to you for free and open access by the Natural Resources, School of at DigitalCommons@University of Nebraska - Lincoln. It has been accepted for inclusion in Papers in Natural Resources by an authorized administrator of DigitalCommons@University of Nebraska - Lincoln. 


\title{
Impacts of irrigation on 20th century temperature in the northern Great Plains
}

\author{
Rezaul Mahmood $^{\text {a,* }}$, Stuart A. Foster ${ }^{\text {a }}$, Travis Keeling ${ }^{\text {a }}$, Kenneth G. Hubbard ${ }^{\text {b }}$, \\ Christy Carlson ${ }^{b}$, Ronnie Leeper ${ }^{\mathrm{a}}$ \\ a Department of Geography and Geology and Kentucky Climate Center, Western Kentucky University, Bowling Green, KY 42101, United States \\ ${ }^{\mathrm{b}}$ High Plains Regional Climate Center, School of Natural Resource Sciences, University of Nebraska-Lincoln, \\ Lincoln, NE 68583-0728, United States
}

Received 29 April 2005; received in revised form 24 July 2005; accepted 21 October 2005

Available online 28 July 2006

\begin{abstract}
Land use change can modify root zone moisture distribution, energy partitioning and subsequently, near surface energy balance. Various modeling studies provided evidence of these changes. For example, land use change from natural grass land to irrigated land use would significantly increase and decrease latent and sensible energy flux, respectively. This type of long-term modification of energy balance would in turn change near surface temperatures. The Great Plains of North America experienced significant overturning of land from natural grass land to irrigated land use during the 20th century. This study provides assessment on the changes in the historical near surface temperature records in Nebraska, USA. Long-term mean monthly maximum, minimum, and monthly mean air temperature data from 5 irrigated and 5 non-irrigated sites were analyzed. Length and homogeneity of time series and stability of stations were primary determinants in selection of these stations. The time series include Cooperative Weather Observation Network (COOP) and Historical Climate Network (HCN) data sets. Pairwise comparisons of temperatures between irrigated and non-irrigated locations for pre- and post-1945, -1950, and -1955 periods were completed for both data sets. These breakdowns of time series helped to identify periods of widespread land use change. Results show notably cooler temperatures over irrigated areas. For example, mean maximum growing season temperature at irrigated Alliance was $0.64{ }^{\circ} \mathrm{C}$ and $1.65{ }^{\circ} \mathrm{C}$ cooler compared to non-irrigated Halsey during pre- and post- 1945 period, respectively. Hence, there was a $1.01{ }^{\circ} \mathrm{C}$ cooling during post-1945 years. Moreover, there has been a greater cooling during the second half of 20th century. The bootstrap re-sampling method was applied and trend analyses were completed for further verification of results. These assessments largely show a decreasing trend in mean maximum growing season temperatures over irrigated areas. To further verify the results and to determine the impacts of extreme values (including extremely cool temperatures), the $20 \%$ trimmed mean approach was applied. The impacts of extreme values have been minimal and based on the results obtained we conclude that land use change in the northern Great Plains has modified near surface temperature records.
\end{abstract}

(C) 2006 Elsevier B.V. All rights reserved.

Keywords: land use change; temperature change; the Great Plains

\footnotetext{
* Corresponding author. Tel.: +1 270745 5979; fax: +1 2707456410 .

E-mail address: rezaul.mahmood@wku.edu (R. Mahmood).
} 


\section{Introduction}

A number of studies noted that over the last 150 years the North American Great Plains has undergone a significant change from natural grass lands to agricultural land use (Ramankutty and Foley, 1999; Waisenan and Bliss, 2002). These changes were most remarkable in the Midwest and the Great Plains. Waisenan and Bliss (2002) reported that in these regions proportions of changes reached close to $60 \%$ of total land area. The changes were greater than 10 fold between 1850 and 1940 and more than 1 fold between 1940 and 1997 for the Midwest and the Great Plains (Waisenan and Bliss, 2002).

In some areas more than $80 \%$ of the land use has changed from non-irrigated to irrigated agriculture (total change 23 fold, from 1950s to 1990s) during the second half of the 20th century (Fig. 1). It is expected that near surface atmospheric temperatures will be modified due to these changes. Due to widespread irrigation more water has been available for evapotranspiration (ET) and latent heat. Near surface warming of air is primarily dependent on sensible energy availability. Since sensible energy partitioning is severely limited due to the land use change, long-term cooling of daily near surface air temperature is expected. In other words, these changes are modifying energy partitioning and budgets.

A soil moisture-energy balance model is applied (Robinson and Hubbard, 1990; Mahmood and Hubbard, 2002; Mahmood and Hubbard, 2003, 2004) for three land uses (natural grass, rainfed and irrigated corn) at three locations in Nebraska to determine changes in land surface-atmospheric interactions and near surface hydrologic conditions. These locations include Mead, Clay Center, and McCook and they represent the east (wet) to west (dry) hydroclimatic gradient of the Great

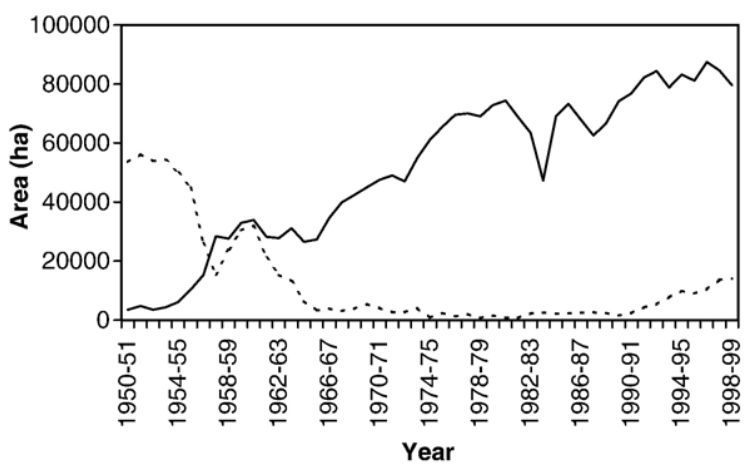

Fig. 1. Land use change in York, Nebraska. Broken and unbroken lines show changes in non-irrigated and irrigated corn land use, respectively.

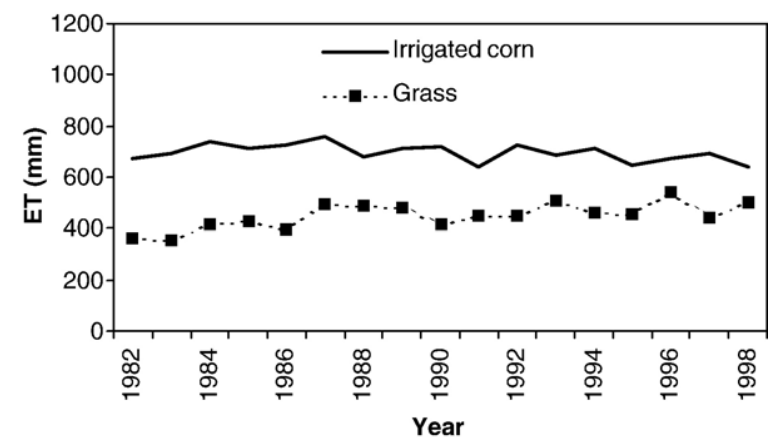

Fig. 2. Evapotranspiration from irrigated and grass land uses.

Plains. The model applications demonstrate that land use change has modified evapotranspiration (ET) and near surface soil moisture amount (thus, energy and water balance). Simulations suggest that at McCook, ET for irrigated maize is nearly $36 \%$ higher than for natural grass (Fig. 2). Moreover, previous applications show notable change in energy partitioning due to these changes (Mahmood et al., 2001). It is expected that a change in energy partitioning of this magnitude should leave an imprint on surface temperature records. In this case, modification of long-term surface temperature records would reflect changes in energy and water budgets.

The key objective of this paper is to further investigate and verify the impacts of the land use change and irrigation on near surface temperature records of the northern Great Plains (NGP) during the growing season. These include: 1) quantifying actual temperature changes over non-irrigated and irrigated areas, 2) identifying period(s) of widespread land use change from temperature records, 3) determining impacts of extreme temperatures (outliers) on overall results, and 4) additional verification of previous findings. It is expected that, due to land use change, the most notable modification of energy balance occurs during the growing season (May through September). Thus, the present study concentrates on this time period. In addition, analyses focus on long-term mean monthly maximum, minimum, mean, and diurnal temperature ranges. In the past, Mahmood et al. (2004) investigated changes in long-term temperature trends due to land use modification. In the present study we have provided additional sets of analyses and assessments which shed new light on the research question posed here.

This study uses two data sets based on the Cooperative Observation Network (COOP) and US Historical Climate Network (USHCN). Both of these sets represent five non-irrigated and five irrigated sites (Fig. 3). Selection of these locations was based on the 


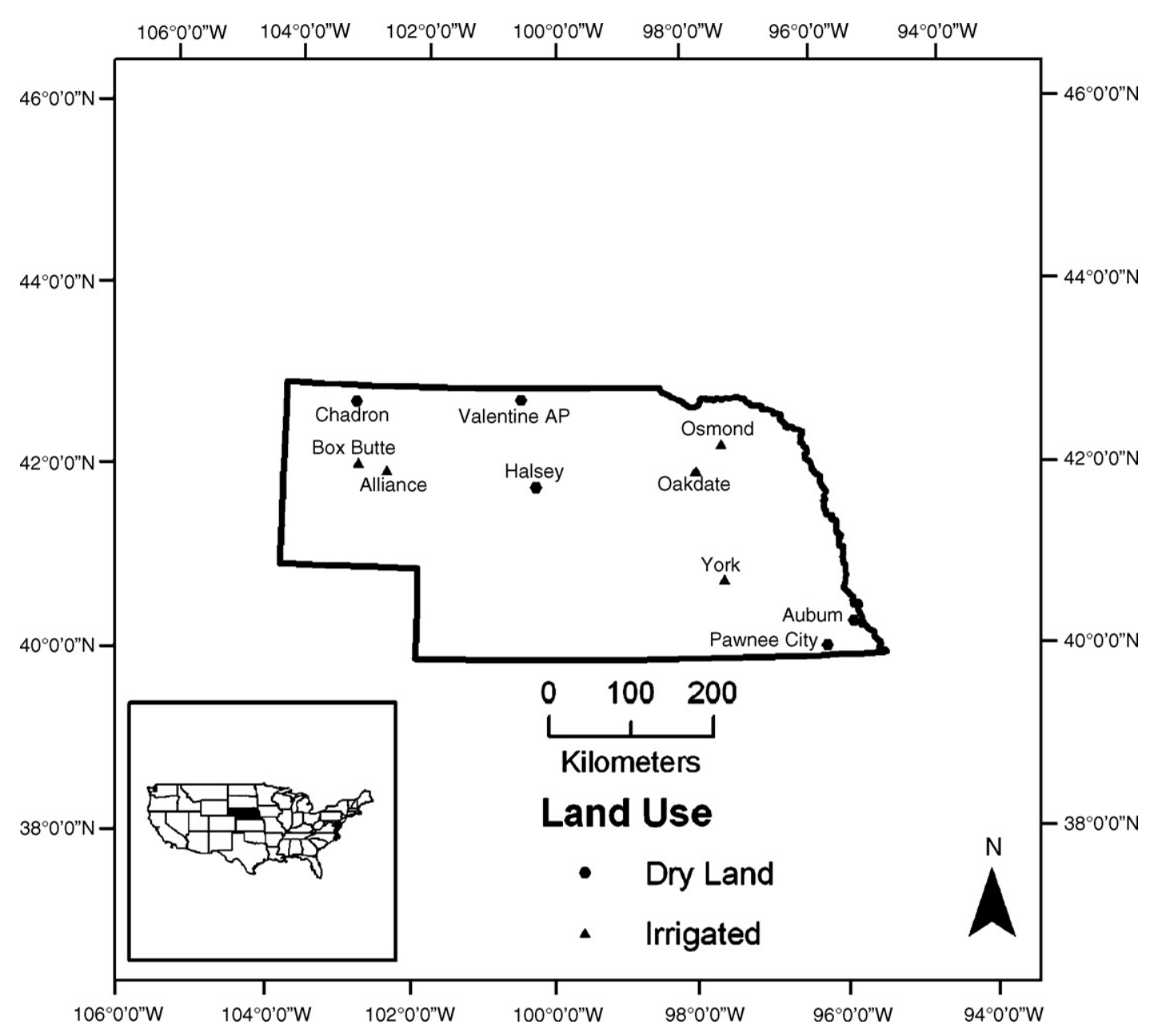

Fig. 3. Location of meteorological stations. (Source: Mahmood et al., 2004).

length of the time series and their surrounding land uses. The HCN data set is developed from the COOP data after applying additional screen and quality assurance procedures. The degree of similarity of results from these two data sets will provide reassurance regarding reliability of results. This study divided both HCN and COOP data sets at 1945, 1950, and 1955 to determine periods of maximum land use change and their impacts on temperatures. In addition, bootstrapping is applied to re-sample the long-term temperature data to further assess the results obtained from observed data. The advantage of bootstrapping compared to other similar methods (e. g, Monte-Carlo simulation) is that it does not assume any particular data distribution (e. g., Gaussian). In addition, we have applied a 20\%-trimmed mean approach to determine the impacts of extreme values and outliers on the results. Details on this can be found in Section 3 of this paper. Pairwise comparison of dew point temperatures from several non-irrigated and irrigated locations has been completed to provide further validation on changes in near surface atmospheric conditions due to land use change.

\section{Background}

Impacts of land use change on the climate system were identified through limited number of observational studies and a significant number of modeling studies. Here we present a summary of the past observational and modeling studies. Analyses of historical temperature records from southern Arizona and northern Mexico suggest land degradation results in higher temperatures in northern Mexico compared to the southern Arizona (Balling, 1988; Balling et al., 1998). The analyses also showed that daily temperature range (DTR) increased on the Mexican side compared to Arizona. Chase et al. (1999) reported that northeast Colorado experienced significant decreases in temperature during the period 
1981-1995. This change was ascribed to large increases in irrigated agriculture (Chase et al., 1999).

Walsh et al. (1985), Chang and Wallace (1987), and Williams (1992) suggested that higher soil moisture content reduced mean monthly temperatures for the current and following months. Durre et al. (2000) reported that on a time scale shorter than one month, the frequency of record and near-record high temperatures is sensitive to soil moisture condition. Physically, energy partitioning is dependent upon surface moistness. If other forcing factors are quasi-static, increased (decreased) soil moisture results in higher (lower) latent (sensible) energy flux. Hence, soil moisture could be a modulator of daily temperatures. Previously, Idso et al. (1981) reported that the surface temperature for irrigated alfalfa could be $12{ }^{\circ} \mathrm{C}$ cooler than the surface temperature of a dry alfalfa field with severe water stress. Segal et al. (1989) found that there was a $10{ }^{\circ} \mathrm{C}$ temperature difference between irrigated and adjoining non-irrigated areas of eastern Colorado.

McPherson et al. (2004) investigated the impacts of the winter wheat belt on the near surface dew point temperature. They used observed air temperatures, dew point temperatures, and vapor pressure deficit data for the study. McPherson et al. (2004) found a cool anomaly of mean maximum temperature over the Oklahoma wheat belt during the growing season. This study also reported higher daily maximum dew point temperature over the wheat belt in March and April. These months coincide with the maximum growth period for the winter wheat. In addition, a lowering of vapor pressure deficit was also found over the Oklahoma winter wheat belt (McPherson et al., 2004).

Cai et al. (2004) and Pielke et al. (2002) noted the two most important anthropogenic impacts on climate to be greenhouse gases and land use changes. However, they have also asserted that the impacts of land use changes have been treated like a noise. Cai et al. (2004) reported that the urban impacts on overall US temperature are relatively small compared to largescale land use changes associated with introduction of agriculture. These observations are in agreement with their assessment that comparative studies of urban and rural stations would be inadequate if impacts of agricultural land uses are excluded.

A modeling work by Roy et al. (2003) suggests up to $1{ }^{\circ} \mathrm{C}$ cooling of mean July surface temperatures over a large part of the Great Plains and the Midwest. The simulations were conducted for July of 1700, 1910, and 1990. Analyses show maximum cooling was concentrated in the central Great Plains of the US, when they compared simulated temperatures from 1910 and 1700 .
A similar comparison for 1990 and 1700 shows spectacular expansion of this cooling over the southern, central and northern Great Plains (Fig. 6; Roy et al., 2003). This finding suggests large changes in the land use in these regions. Roy et al. (2003) note that changes in land use from grass land to farm lands have potentially increased evapotranspiration and thus lowered the Bowen ratio and temperature.

Eastman et al. (2001) conducted a model-based study on the impacts of changes in vegetation coverage on various atmospheric parameters. This study largely focused on the central and northern Great Plains. They demonstrated that under potential future natural vegetation coverage mean maximum temperature would be $1.2{ }^{\circ} \mathrm{C}$ cooler compared to current land uses.

Marland et al. (2003) suggest that land surface change would affect regional and global climate by modifying surface albedo and energy budgets. However, it is recognized that land use change and its potential impacts are not explicitly included in climate change mitigation policies. Hansen et al. (1998) and Betts (2001) estimated that land use change has an annual mean forcing of -0.21 and $-1 \mathrm{Wm}^{-2}$, respectively. Hoffman and Jackson (2000) showed that changes of Savannah to grass land would change surface albedo and energy budgets and subsequently precipitation. It is argued that since land surface is an important component of the climate system, land surface changes and their impacts should be seriously considered (Marland et al., 2003). Therefore, the present study addresses these concerns.

A modeling study by Marshall et al. (2004) demonstrated that land use change has modified summertime local temperature and precipitation in peninsular Florida. This study has focused on the pre-1900 natural and current land uses. They found that energy partitioning (sensible and latent) has changed notably. In addition, modifications in spatial distribution of convective rainfall have occurred and daily maximum temperature has increased. These changes are physically consistent with our general understanding of the behavior of meso-scale circulation and energy budgets under various land surface forcing. For example, draining of natural wetlands to agricultural fields will significantly reduce latent energy partitioning and thus increase daytime temperature. The increase in modeled temperature is consistent with observed records. The simulations indicate that near surface daily maximum temperature would reach its maximum point at an earlier time (phase shift) under current land use (Marshall et al., 2004). Obviously, the recent drying of the land surface played a key role in the phase shift. In a related study, 
Marshall et al. (2003) argued that present-day land use in the key agricultural areas of peninsular Florida has resulted in greater severity and frequency of freezing conditions. Model simulations show that for the natural land use in pre-1900 a persistent heat flux would originate in the wetlands and force temperatures to remain above freezing level.

Recently, Narisma et al. (2003) investigated the impacts of land cover change on January temperatures in Australia. Land uses for 1850 and 2000 were used. In this modeling study, experiments were set up to allow biospheric feedback and no feedback. It has been found under both experiments that latent energy flux will increase and temperature will decrease over NE Australia. In another study, Pitman et al. (2004) estimated that land cover change explains $50 \%$ of the observed warming in southwestern Australia.

Bounoua et al. (2000) completed a model-based study and applied global NDVI data from 1982-1990 to develop maximum and minimum vegetation scenarios. They reported a $1.8 \mathrm{~K}$ cooling during the growing season in the northern latitudes due to a greater amount of energy partitioned into latent heat. Moreover, it is reported that soil dryness changes this partitioning (Bounoua et al., 2000). This clearly suggests that: (1) under irrigated condition plants will use more water; and (2) irrigation will lead to higher soil moisture content. Both of these conditions will lead to higher latent energy flux and subsequent reduction in near surface temperature. The impact potentially is largest on daily maximum temperature because it occurs frequently in late afternoon which coincides with the active transpiring phase of plants.

Hogg et al. (2000) assessed the forcing of deciduous forest phenology on seasonal climatic pattern in the western Canadian interior and found $2{ }^{\circ} \mathrm{C}$ cooling of summer time temperature. They suggest that latent heat flux increases when leaves start to appear and dominates the energy partitioning during summer (Hogg et al., 2000).

Zhao and Pitman (2002) completed a modeling study to determine the impacts of land cover change and increasing $\mathrm{CO}_{2}$ on maximum temperature frequency and convective precipitation. Coupled NCAR CCM3 and BATS were used and reported a reduction in the return value of maximum temperature in Europe. They have concluded that replacement of deciduous forest with croplands over Europe reduced stomatal resistance and this led to higher latent energy fluxes and lowering of temperatures (Zhao and Pitman, 2002). This study suggests that land cover change resulted in a $2{ }^{\circ} \mathrm{C}$ reduction of maximum temperature in Europe and the level of $\mathrm{CO}_{2}$ did not make any difference in this estimate. Thus, impact of land cover change on temperature was independent of atmospheric concentration of $\mathrm{CO}_{2}$.

In a separate modeling study, Bounoua et al. (2002) found that in the temperate latitudes land use transformation to crop land would reduce summer temperature up to $0.7^{\circ} \mathrm{C}$. They have noted that morphological and physiological changes in vegetation resulted in increased latent energy flux and reduction of temperature.

Chase et al. (2000) demonstrated that the tropical land use change may have a forcing similar to El Nino and may result in modifying surface fluxes in a distant region through non-linear atmospheric feedback. El Nino and La Nina changes are cyclic while land use change usually occurs in one direction (Pielke et al., 2002). Also, in most of the cases regional land use changes occur over a longer time period. Thus, largescale land use change is generally a slower process, and its impacts may not be as obvious. Pielke et al. (2002) suggested that energy partitioning directly influences near surface temperature and should be considered as climate forcing.

Due to the non-linear nature of atmospheric feedbacks, land use changes in remote places may have opposing impacts on local and regional climate and spatial averaging may hide actual conditions. This would result in incorrect quantification of climate systems (Pielke et al., 2002). He concluded that if we exclude land use changes and their impacts on the climate system, agreements between general circulation model (GCM) simulations and observations may be due to 'wrong reasons' (Pielke, 2002). Additionally, he suggests that we need to test the hypotheses that: (1) landscape directly and indirectly influences earth's radiation budget; (2) land use change affects local, regional and global climate at all time scales; and (3) forcing due to land use change is as important as radiative forcing associated with a doubling of carbon dioxide.

It is clear from the above discussion that changes in land use have a profound effect on the atmosphere and climate system. This includes impacts on near surface temperatures. Furthermore, widespread introduction of agriculture would modify growing season temperatures. However, there is a lack of studies directly comparing impacts of non-irrigated and irrigated land uses on near surface temperature using observed data. This study compares and analyzes temperature data from irrigated and non-irrigated areas and thus provides a more direct approach to the research questions posed. Moreover, the length of time series used is longer than for previous 
studies. The authors note that while nearly all of the previous studies have relied heavily on the modeling approach (for justifiable reasons), there is a general lack of detailed observed temperature based assessment. The present observational study responds to this need and fills a critical void in the literature. In addition, it will be shown that the results of the present study are in agreement with the physical reasoning shown in the above studies.

\section{Data and methods}

This study analyzed long-term growing season mean monthly maximum, minimum, and mean air temperature data from five irrigated and five nonirrigated sites (Fig. 3 and Table 1). The length of the time series, classification as primarily non-irrigated or irrigated land area, completeness of record, and stability of station location were key factors in the selection process. All stations are part of the Cooperative Observation Network (COOP) and several of these COOP sites (see Table 1) are part of the Historical Climate Network (HCN). HCN designation for selected sites was given after passing screening and quality control procedures as developed by the National Climatic Data Center (NCDC). Data from the $\mathrm{HCN}$ is also analyzed for these same locations to determine whether their adjustments and screening affected the results. We have incorporated data from Pawnee City for which only $\mathrm{HCN}$ time series is available. York, Osmond, Oakdale, Box Butte, and Alliance are primarily surrounded by irrigated land use while Halsey, Chadron, Auburn, Valentine AP, and Pawnee City are representative of non-irrigated land use. University of Nebraska-Lincoln (UNL) developed a data set and map of center pivot irrigation for Nebraska (UNL, 2000). We have used latitude and longitude of stations in this study along with this map to determine whether the land use surrounding a station is irrigated or non-irrigated.

In order to establish the impacts of land use change on long-term temperature a number of steps were taken including a pairwise comparison of mean maximum, mean minimum and mean growing season temperatures of non-irrigated and irrigated locations for both COOP and $\mathrm{HCN}$ sites. Data from three irrigated locations including Alliance, Oakdale, and York and three nonirrigated locations including Halsey, Pawnee City, Auburn, were analyzed for this purpose. This subgroup of six stations represents the longest records. The comparison is completed by subtracting (irrigated minus non-irrigated) 1906-1945 temperatures of Alliance from Auburn, Halsey, and Pawnee City; of Oakdale from Auburn, Halsey, and Pawnee City; of York from Auburn, Halsey, and Pawnee City. Similar comparison is conducted for 1946-1999 time period. Pairwise comparison helps to identify impacts of dissimilar land surface conditions on temperature records because impacts of similar forcing cancel each other. For example, if the large-scale atmospheric circulation pattern affects temperature of a region during a particular season in a certain way, it is expected that impacts would be similar at both sites and pairwise comparison of temperature would cancel each other. However, if these two sites represent a pre-dominantly irrigated and a non-irrigated area, the forcing of these two land uses would modify temperature time series reflecting underlying conditions.

We find that an extraordinary amount of land has changed from non-irrigated to irrigated land use during the late 1940 s to early 1950 s. Therefore, to determine the maximum impacts of these changes on temperature, the data set is also divided in time periods of 1906-1950 and 1951-1999 and also between 1906-1955 and

Table 1

List of Cooperative and $\mathrm{HCN}$ station locations and associated land uses for pairwise comparison

\begin{tabular}{lllll}
\hline Station name & County & Land use & Station status & $\begin{array}{l}\text { Length of time series (Coop, HCN) } \\
\text { used for pairwise comparisons }\end{array}$ \\
\hline York & York & Irrigated & Cooperative, HCN & $1921-1990,1906-1999$ \\
Oakdale & Antelope & Irrigated & Cooperative, HCN & $1921-1990,1906-1999$ \\
Alliance & Box Butte & Irrigated & Cooperative, HCN & $1921-1990,1906-1999$ \\
Osmond & Pierce & Irrigated & Cooperative & $1948-2000$ \\
Box Butte & Box Butte & Irrigated & Cooperative & $1949-1981$ \\
Halsey & Thomas & Non-irrigated & Cooperative, HCN & $1921-1990,1906-1999$ \\
Auburn & Nemaha & Non-irrigated & Cooperative, HCN & $1921-1990,1906-1999$ \\
Pawnee City & Pawnee & Non-irrigated & HCN & $1906-1999$ \\
Valentine AP & Cherry & Non-irrigated & Cooperative & $1948-2000$ \\
Chadron & Daws & Non-irrigated & Cooperative & $1948-2000$ \\
\hline
\end{tabular}


1956-1999. The authors are aware that latitude-wise, northern stations are going to be generally cooler compared to southerly sites (which is a function of latitudinal distribution of solar radiation). However, range of latitudinal distribution is only about $2^{\circ}$ and analyses are completed for warm months only, when impact of this latitudinal distribution on temperature is almost non-existent (cf., Balling, 1988). Moreover, division of time series between pre- and post-1945 and calculation of magnitude of cooling for each segment and for each pair eliminated the possibilities of bias in results. For example, if a northerly located irrigated location is cooler (say $0.5^{\circ} \mathrm{C}$ ) compared to a southerly located non-irrigated site during first half of the 20th century and the magnitude of coolness is greater (say $1{ }^{\circ} \mathrm{C}$ ) during the second-half of the 20th century then it can be concluded that there is a $0.5^{\circ} \mathrm{C}$ cooling. Hence, in this case impact of latitude has been removed. In addition, it clearly demonstrates the impacts of land use change on long-term temperatures in the two halves of the 20 th century.

The bootstrapping method (cf., Mooney and Duval, 1993 ) is applied to re-sample the COOP and HCN data from each location for mean maximum, mean minimum, mean temperatures, and mean temperature ranges (DTR) for the growing season. Re-sampling was used to create 1000 data sets for each of the parameters at each location. In addition, significance tests for slopes of linear trends are performed to further assess the validity of results.

It is well known that extreme values affect the distribution and results of any study. We adopted the Yuen-Welch approach (Wilcox, 1997) that allowed us to omit $20 \%$ of the extreme values from each tail of the re-sampled temperature data $(20 \%$-trimmed mean approach). Agreement of pairwise comparison results (significant at 95\%) between original distribution and the trimmed re-sampled distribution without extreme values provided further confidence in the outcome of the analyses.

The High Plains Regional Climate Center (HPRCC) maintains a meso-network, known as the Automated Weather Data Network (AWDN). The stations under this network measure and record dew point temperature. The period of record for some of these stations exceeds 20 years. Dew point temperature provides an accurate measure of atmospheric moistness. Thus, it is expected that irrigated locations would experience higher growing season dew point temperature compared to nonirrigated areas. As noted above, pairwise comparison is completed for selected irrigated and non-irrigated locations for this purpose.

\section{Results}

\subsection{The HCN time series-based pairwise comparison} of growing season temperatures for 1906-1945 and 1946-1999

Here we present magnitude of cooling at irrigated and non-irrigated locations during pre-1945 and post1945. In the following discussion a station followed by I or NI indicates irrigated or non-irrigated locations respectively. Results based on $\mathrm{HCN}$ data show that mean maximum temperatures at Alliance (I) and Oakdale (I) during pre-1945 years were lower compared to NI Auburn, Halsey, Pawnee City while York was warmer compared to these non-irrigated areas. For example, mean maximum growing season temperature at Alliance was $2.41{ }^{\circ} \mathrm{C}$ colder compared to Auburn while Oakdale was $2.18^{\circ} \mathrm{C}$ colder compared to Pawnee City (Fig. 4). Comparison of post-1945 data for irrigated and non-irrigated locations shows similar results. However, in most cases, it is found that cooling was greater at irrigated locations during post-1945 period compared to pre-1945 years. For example, mean maximum growing season temperature at Alliance was $0.64{ }^{\circ} \mathrm{C}$ and $1.65^{\circ} \mathrm{C}$ cooler compared to Halsey during pre- and post- 1945 period, respectively (Fig. 4). Thus, there was a $1.01{ }^{\circ} \mathrm{C}$ cooling during post- 1945 years (Fig. 5). Moreover, it is found that York has become colder during post-1945 period compared to Auburn and Pawnee City (York was warmer compared to these sites during pre-1945 years). Compared to pre-1945 years and for these locations, York has cooled down 0.44 and $1.26{ }^{\circ} \mathrm{C}$ during post-1945 years, respectively (Fig. 5). In addition, York remained $0.18{ }^{\circ} \mathrm{C}$ warmer

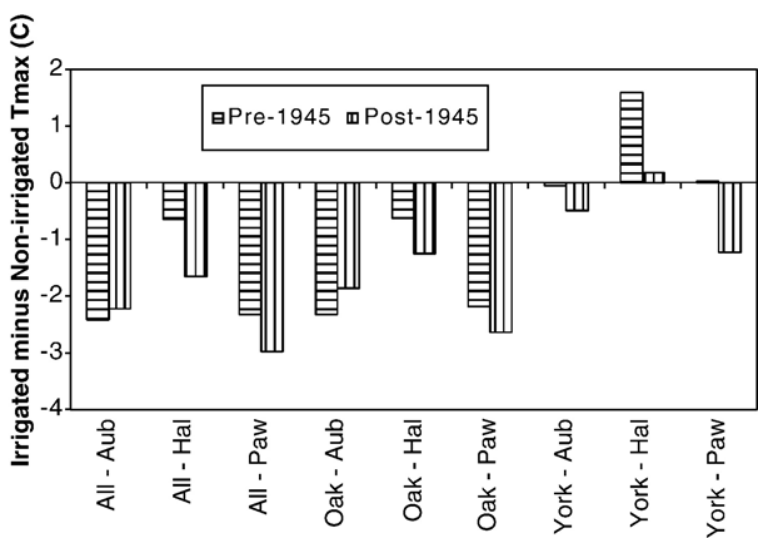

Fig. 4. Difference between growing season mean maximum temperatures at irrigated and non-irrigated locations for pre-1945 and post-1945 years. 


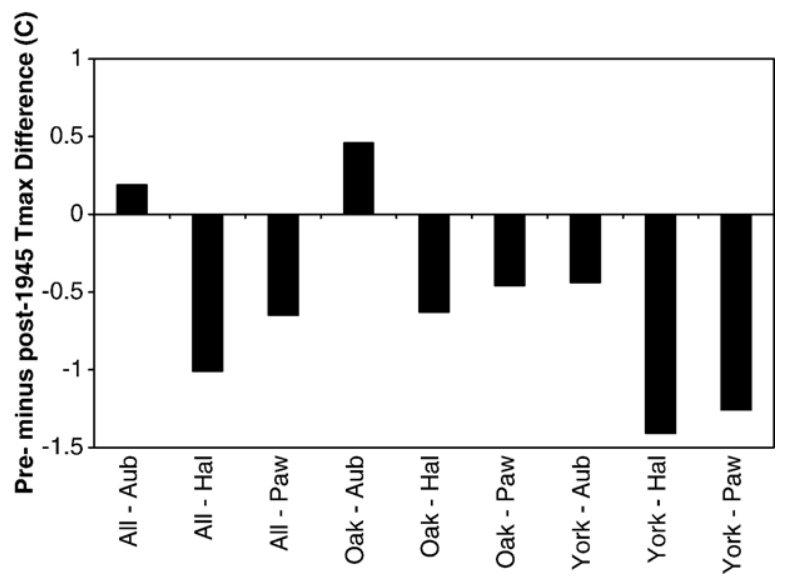

Fig. 5. Difference between growing season mean maximum temperatures at irrigated and non-irrigated locations for pre-1945 minus difference between growing season mean maximum temperatures at irrigated and non-irrigated locations for post-1945 years.

compared to Halsey during post-1945 period. However, note that it has cooled down $1.41{ }^{\circ} \mathrm{C}$ during post 1945 period (Figs. 4 and 5). A composite difference also found greater cooling during this period (Fig. 6). Further summary of results suggest that, on the average, irrigated locations cooled down $0.58{ }^{\circ} \mathrm{C}$ during post1945 (Fig. 7). In summary, the second half of the 20th century experienced greater cooling, primarily due to the introduction of irrigation.

Pairwise analyses of growing season mean minimum temperatures for pre-1945 years demonstrate that in seven out of nine cases, locations classified as primarily irrigated land use are cooler than non-irrigated sites. For example, mean minimum temperature at Alliance was 4.96 and $5.03{ }^{\circ} \mathrm{C}$ cooler compared to Auburn and Pawnee City, respectively (Fig. 8). Post-1945 years

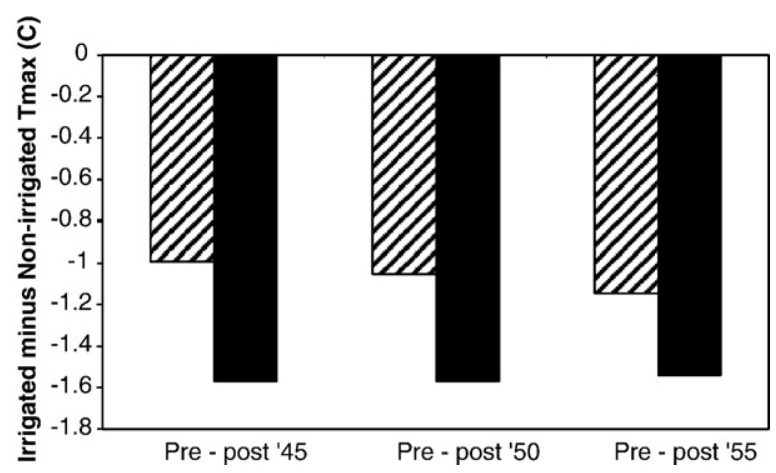

Fig. 6. Composite difference between growing season mean maximum temperatures at irrigated and non-irrigated locations. Shaded and black bars indicate the first- and second-half of the 20th century, respectively.

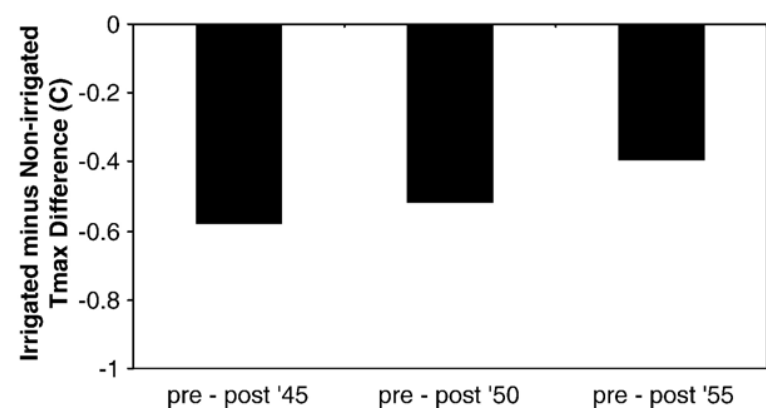

Fig. 7. Composite difference between growing season mean maximum temperatures at irrigated and non-irrigated locations for the first-half of the 20th century minus difference between growing season mean maximum temperatures at irrigated and non-irrigated locations for the first-half of the 20th century.

show similar results for these locations. However, five pairwise comparisons show reduced differences (slight warming) between irrigated and non-irrigated land use during post-1945 years (Fig. 8). On the other hand, the remaining four pairwise comparisons suggest greater cooling at irrigated locations during post-1945 compared to pre-1945 years. A composite difference found, on the average, that nearly no warming over irrigated areas (Figs. 9 and 10). These mixed results and absence of clear signals are consistent with the trend analyses of temperature data, completed by Mahmood et al. (2004). Further discussion of results is presented in Sections 4.6 and 5.

Pairwise comparisons of growing season mean temperature indicate that irrigated locations were up to $4.11{ }^{\circ} \mathrm{C}$ cooler compared to non-irrigated areas during pre-1945 years (Fig. 11). This pattern of cooling

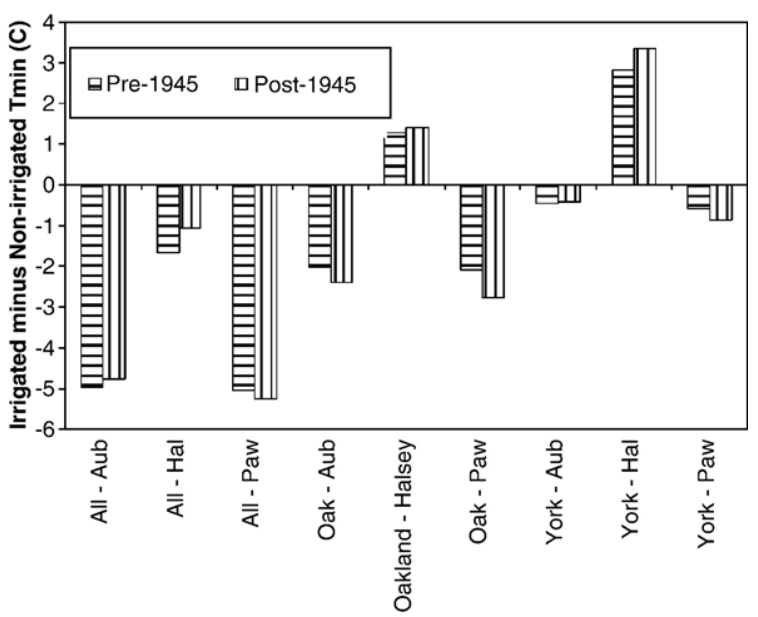

Fig. 8. Difference between growing season mean minimum temperatures at irrigated and non-irrigated locations for pre-1945 and post1945 years. 


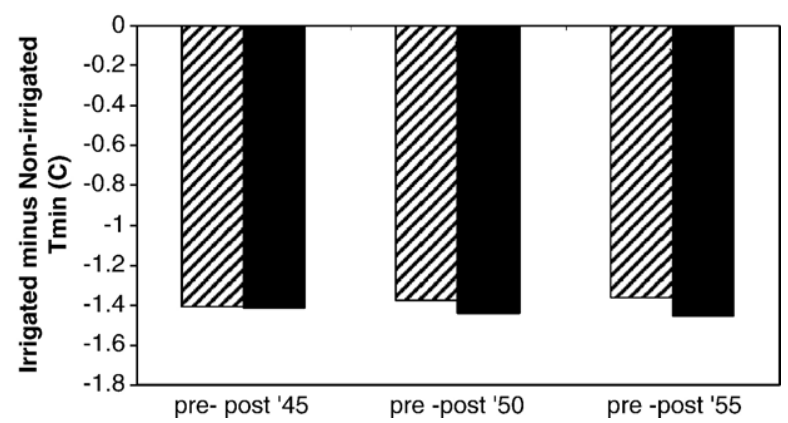

Fig. 9. Composite difference between growing season mean minimum temperatures at irrigated and non-irrigated locations. Shaded and black bars indicate the first- and second-half of the 20th century, respectively.

continued for post-1945 years and it is found that in most cases magnitude of cooler mean temperature was greater during post-1945 years compared to pre-1945s. For example, compared to Pawnee City, York was 0.27 and $1.04{ }^{\circ} \mathrm{C}$ cooler during pre-1945 and post-1945 years, respectively (Fig. 11). In other words, mean temperature at York has cooled down further $0.77{ }^{\circ} \mathrm{C}$ compared to Pawnee City.

\subsection{The HCN time series-based pairwise comparison} of growing season temperatures for 1906-1950 and 1951-1999

Differences in growing season mean maximum temperature between irrigated and non-irrigated locations show generally similar results for $1906-1950$ as compared to 1906-1945. Hence, irrigated locations were cooler compared to most of the non-irrigated locations. However, most of the pairwise comparisons suggest that these lower mean maximum temperatures for irrigated areas for 1906-1950 are cooler than 19061945 time period. For example, Oakdale (I) was 0.62

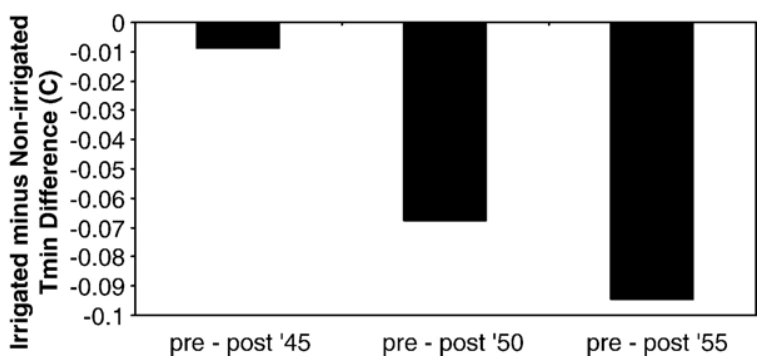

Fig. 10. Composite difference between growing season mean minimum temperatures at irrigated and non-irrigated locations for the firsthalf of the 20th century minus difference between growing season mean minimum temperatures at irrigated and non-irrigated locations for the first-half of the 20th century.

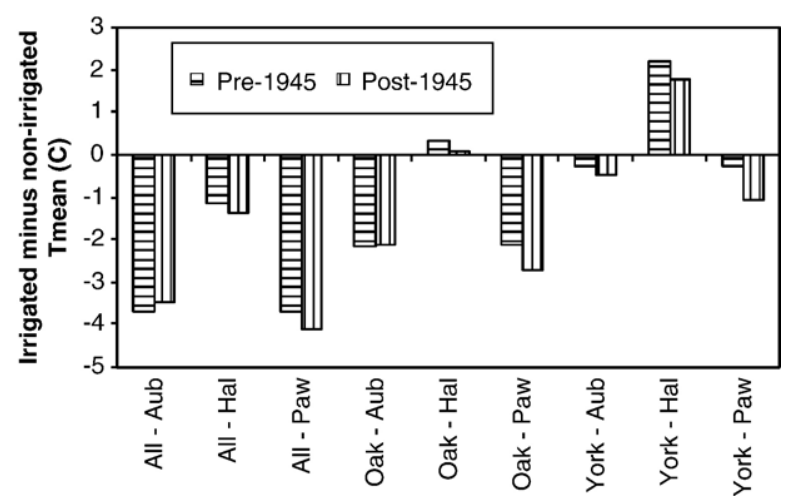

Fig. 11. Difference between growing season mean temperatures at irrigated and non-irrigated locations for pre-1945 and post-1945 years.

and $0.74{ }^{\circ} \mathrm{C}$ cooler compared to Halsey (NI) during 1906-1945 and 1906-1950 period, respectively (Fig. 12). This difference in magnitude of cooling due to the point (year) of division of time series also indicates that land use change during the late 1940s significantly affected and modified long-term temperature. Analyses of data from 1951-1999 suggest a continued cooling of growing season mean maximum temperature, as also indicated by 1946-1999. For example, Alliance (I) and Oakdale (I) were 3.00 and $2.61{ }^{\circ} \mathrm{C}$ cooler compared to Pawnee City (NI), respectively, during 1951-1999 period. Compared to the pre-1950s, 0.62 and $0.36{ }^{\circ} \mathrm{C}$ cooling has occurred during post-1950s years for these locations, respectively. As expected, a composite difference also suggests greater cooling during 19061950 period compared to 1906-1945 (Fig. 6). During further summarization of data we have found that combination of this greater cooling during pre-1950 and nearly unchanged cooling for post-1950 resulted in $0.52{ }^{\circ} \mathrm{C}$ overall cooling over irrigated locations (Fig. 7). We recommend that this type of summarization should

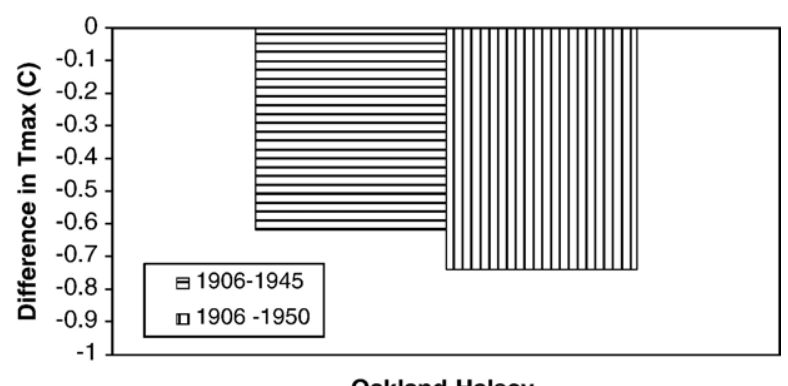

Oakland-Halsey

Fig. 12. Difference between growing season mean maximum temperatures at irrigated and non-irrigated locations for pre-1945 and pre1950 years. 
be used in conjunction with other analyses (e.g. Fig. 6) for accurate understanding of findings. Overall, again, second-half of 20th century is cooler over irrigated land uses compared to first-half.

Analyses of data clearly indicate that the growing season mean minimum temperature over irrigated areas has been lower compared to non-irrigated sites during both pre- and post-1950 period. It is found that, for example, Alliance and Oakdale have been 4.96 and $2.06{ }^{\circ} \mathrm{C}$ cooler, respectively, compared to Pawnee City during 1906-1950. Moreover, these sites have been 5.32 and $2.87{ }^{\circ} \mathrm{C}$ cooler compared to Pawnee City for 1951-1999 period. As shown in Section 4.1, data analyses also show warming for four pairwise comparisons between irrigated and non-irrigated sites.

Pairwise comparisons produced a greater magnitude of difference between irrigated and non-irrigated locations for the period 1951-1999, compared to 19061950 , in seven out of nine cases. In addition, the magnitude of differences (1951-1999) for six of these pairs are greater, when we divided the time series at 1950 instead of 1945 . Growing season mean temperature analysis also clearly shows up to 3.67 and $4.16{ }^{\circ} \mathrm{C}$ cooling over irrigated areas for 1906-1950 and $1951-$ 1999 time periods, respectively.

\subsection{The HCN time series-based pairwise compari-} son of growing season temperatures for 1906-1955 and 1956-1999

Again, despite the changes in point of division of the time series temperatures from irrigated sites clearly suggest a cooling compared to the non-irrigated locations. Analysis of mean maximum temperature indicates that, for example, Oakdale was $2.29^{\circ} \mathrm{C}$ cooler compared to Pawnee City, respectively, during 19061955 period. Seven of nine pairwise comparisons suggest that the second half of 20th century was cooler for irrigated locations compared to the first-half. However, it is also found that cooling at irrigated locations was greatest during 1906-1955, compared to 1906-1945 and 1906-1950 periods, in all but two cases. This suggests significant impacts of land use change during 1945-1955 and their impacts on magnitude of cooling of mean maximum growing season temperature. Additional discussion on this is given below.

Difference in the magnitude of cooling of mean maximum temperature between pre- and post-1955 was less compared to when time series was divided at 1945 and 1950 (Fig. 13). This, again, suggests significant increases in irrigated agriculture during the late 1940s and early 1950s and its subsequent impacts on mean maximum temperatures. It is clear so far that magnitude of cooling was greater during the second-half of 20th century. Note that this study shifted the dividing point (year) of time series from 1945 to 1955, to determine the years of significant impact. Division of time series at 1955 included the years of some significant land use and subsequent temperature changes of 1945-1955. In addition, as a result of this division in 1955, compared to previous sets (Sections 4.1 and 4.2) of pairwise analyses, difference in magnitude of cooling of mean maximum growing season temperature has decreased between first and second-half of 20th century (Figs. 6 and 7).

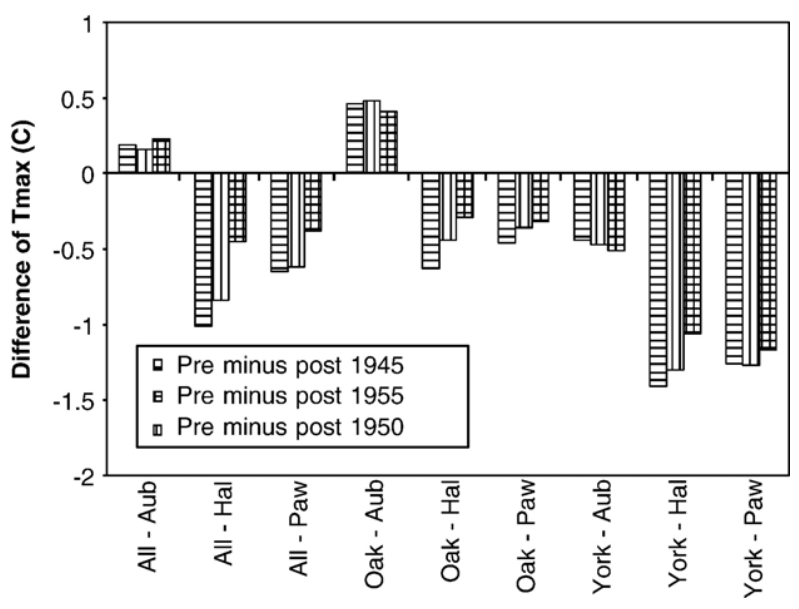

Fig. 13. Difference between growing season mean maximum temperatures at irrigated and non-irrigated locations for pre-1945, pre-1950, pre-1955 minus difference between growing season mean maximum temperatures at irrigated and non-irrigated locations for post-1945, post-1950, and post1955 years, respectively. 
Mean minimum (Fig. 10) and mean growing season temperature clearly suggest a cooling over irrigated land uses. Six of nine pairwise analyses suggest that mean minimum growing season temperatures around irrigated areas were cooler during 1956-1999 period compared to 1946-1999 and 1951-1999. Nonetheless, four of nine pairwise comparisons also suggest warming of mean minimum growing season temperature. Again, see Sections 4.6 and 5 for explanation of this finding.

\subsection{The COOP time series-based pairwise comparison} of growing season temperatures for 1921-1945, 1946-1990, 1921-1950, 1951-1990, 1921-1955 and 1956-1990

The COOP time series-based analyses, in addition to the HCN time series, were conducted to determine whether use of data sets with limited screening produce different results. The results based on COOP data set suggest cooling over irrigated areas and thus agrees with the HCN data set based results. For example, mean maximum temperature at irrigated Oakdale was $1.32{ }^{\circ} \mathrm{C}$ cooler compared to non-irrigated site Halsey during 1946-1990 period. The agreement of results, based on two different data sets, provides further confidence in findings. The COOP data for Pawnee City was not available during this study which results in six pairwise analyses, instead of nine. Moreover, data for the COOP location Halsey ends in 1990 and hence the analyses extended through 1990 instead of 1999.

\subsection{Results from $20 \%$-trimmed mean assessment}

It is well known that outliers or extreme values in a time series affect distribution and subsequently results of a study. To further verify the above results, we have omitted outliers from the lower and upper end of the re-sampled temperature data and performed pairwise analysis similar to Sections 4.1-4.3. We have applied bootstrapping for re-sampling and trimmed mean method for omitting $20 \%$ of the outliers from each tail of the distribution. Note that the only difference is that the length of the time series for both actual and re-sampled data for all locations is 1921 through 1990. Coop data sets for York and Halsey start and end in 1921 and 1990, respectively. To match this, HCN data are truncated also. Subsequently, pairwise comparisons and significance testing (95\%)

Table 2

Results from pairwise comparisons of pre-minus post-1950 growing season temperatures and their significance (95\%, shown with an *) for original data set and re-sampled trimmed $(20 \%$ on each tail) data. Similarity suggests superior confidence in results. OD $=$ Original data; RSTD $=$ Re-sampled trimmed $(20 \%)$ on each tail

\begin{tabular}{|c|c|c|c|}
\hline $\begin{array}{l}\text { Irrigated (I) and non-irrigated (NI) } \\
\text { locations }\end{array}$ & $\begin{array}{l}\text { Alliance (I-OD) Alliance } \\
(I-R S T D)\end{array}$ & $\begin{array}{l}\text { Oakland (I-OD) Oakland } \\
(I-R S T D)\end{array}$ & $\begin{array}{l}\text { York (I-OD) York } \\
(I-R S T D)\end{array}$ \\
\hline \multicolumn{4}{|c|}{ Growing season mean maximum temperature } \\
\hline Auburn (NI-OD) & Warmer & Warmer* & Cooler* \\
\hline Auburn (NI-RSTD) & Warmer & Warmer* & Cooler* \\
\hline Halsey (NI-OD) & Cooler* & Cooler & Cooler* \\
\hline Halsey (NI-RSTD) & Cooler* & Cooler & Cooler* \\
\hline Pawnee City (NI-OD) & Cooler* & Cooler* & Cooler* \\
\hline Pawnee City (NI-RSTD) & Cooler* & Cooler* & Cooler* \\
\hline \multicolumn{4}{|c|}{ Growing season mean minimum temperature } \\
\hline Auburn (NI-OD) & Warmer & Cooler* & Cooler \\
\hline Auburn (NI-RSTD) & Warmer & Cooler* & Cooler \\
\hline Halsey (NI-OD) & Warmer* & Warmer & Warmer* \\
\hline Halsey (NI-RSTD) & Warmer* & Cooler & Warmer* \\
\hline Pawnee City (NI-OD) & Cooler* & Cooler* & Cooler* \\
\hline Pawnee City (NI-RSTD) & Cooler & Cooler* & Cooler \\
\hline \multicolumn{4}{|l|}{ Growing season mean temperature } \\
\hline Auburn (NI-OD) & Warmer & Warmer & Cooler* \\
\hline Auburn (NI-RSTD) & Warmer & Cooler & Cooler \\
\hline Halsey (NI-OD) & Cooler & Cooler & Cooler* \\
\hline Halsey (NI-RSTD) & Cooler* & Cooler & Cooler* \\
\hline Pawnee City (NI-OD) & Cooler* & Cooler* & Cooler* \\
\hline Pawnee City (NI-RSTD) & Cooler* & Cooler* & Cooler* \\
\hline
\end{tabular}


of differences have been completed using original (1921-1990) and trimmed re-sampled data sets. The results show remarkable similarity for growing season mean maximum, mean minimum, and mean temperatures for both data sets. For example, seven of nine pairwise comparisons of $\mathrm{HCN}$ mean maximum growing season temperature between irrigated and non-irrigated locations for pre- and post-1950 show that the differences are significant (95\% level) (Table 2). Application of $20 \%$-trimmed mean approach to resampled data agrees with this result (Table 2). It is also found that 52 of 54 pairwise comparisons (shown in Table 2) for original data and re-sampled trimmed data for pre- and post-1950 are in agreement in their outcome. These similarities in results suggest that extreme values or outliers did not play a key role in cooling. In other words, land use change and its persistent forcing resulted in the cooling. The results from pre- and post-1945 and pre- and post-1955 demonstrate similar statistically significant (95\%) results for most of the pairwise comparisons for original and re-sampled trimmed data sets for mean maximum, mean minimum and mean growing season temperatures (not shown here).

\subsection{Re-sampling of the data and further assessment of impacts of land use change on temperature}

In the past Mahmood et al. (2004) analyzed the same COOP and HCN data set and found negative long-term trends in growing season mean maximum, mean daily temperature range (DTR), and average temperatures for irrigated locations. To further verify these results we have applied the bootstrapping method to re-sample and simulate new data sets. One of the advantages of re-sampling is that it provides larger data sets for additional assessment of results. Moreover, bootstrapping does not assume a gaussian distribution for data from the time series. Therefore, re-sampling and subsequent analyses provide a more rigorous verification of results. In this study, for each location 1000 re-sampled data sets were developed for each temperature parameter for the $\mathrm{HCN}$ and COOP time series. An assessment of trend and a significance test with $95 \%$ confidence interval was completed using these re-sampled data. The simulated COOP data sets indicate a decreasing trend for daily temperature range (DTR) at four (two of them are statistically significant at $95 \%$ confidence level) of the five irrigated locations (Table 3). All three HCN data sets for irrigated locations also show decreasing DTR and all of them are significant at $95 \%$ level. These trends agree with
Table 3

Rate of growing season temperature changes for 10 locations in Nebraska

\begin{tabular}{|c|c|c|c|c|}
\hline $\begin{array}{l}\text { Location and length } \\
\text { of time series: } \\
\end{array}$ & \multirow[t]{3}{*}{$\begin{array}{l}\text { Mean } \\
\text { temp. }\end{array}$} & \multirow[t]{3}{*}{$\begin{array}{l}\text { Mean } \\
\text { max. } \\
\text { temp. }\end{array}$} & \multirow[t]{3}{*}{$\begin{array}{l}\text { Mean } \\
\text { min. } \\
\text { temp. }\end{array}$} & \multirow[t]{3}{*}{ DTR } \\
\hline \multirow{2}{*}{$\frac{\mathrm{COOP}}{\mathrm{HCN}}$} & & & & \\
\hline & & & & \\
\hline \multicolumn{5}{|l|}{ York (I): } \\
\hline 1921-2000 & -0.0109 & -0.0100 & 0.0015 & -0.0113 \\
\hline $1901-1999$ & -0.0007 & -0.0100 & 0.0090 & -0.0190 \\
\hline \multicolumn{5}{|l|}{ Osmond (I): } \\
\hline $\begin{array}{l}1948-2000 \\
\text { Not available }\end{array}$ & 0.0006 & -0.0100 & 0.0107 & -0.0201 \\
\hline \multicolumn{5}{|l|}{ Oakdale (I): } \\
\hline 1893-2000 & -0.0010 & -0.0042 & 0.0030 & -0.0071 \\
\hline 1894-1999 & -0.0010 & -0.0046 & 0.0020 & -0.0066 \\
\hline \multicolumn{5}{|l|}{ Boxbutte (I): } \\
\hline $\begin{array}{l}\text { 1949-1981 } \\
\text { Not available }\end{array}$ & -0.0037 & -0.0061 & -0.0018 & -0.0042 \\
\hline \multicolumn{5}{|l|}{ Alliance (I): } \\
\hline 1894-2000 & -0.0025 & -0.0011 & -0.0039 & 0.0030 \\
\hline $1901-1999$ & 0.0030 & -0.0011 & 0.0086 & -0.0010 \\
\hline \multicolumn{5}{|l|}{ Halsey (NI): } \\
\hline 1904-1990 & 0.0053 & 0.0097 & 0.0009 & 0.0087 \\
\hline $1903-1998$ & -0.0005 & -0.0014 & -0.0005 & -0.0010 \\
\hline \multicolumn{5}{|l|}{ Chadron (NI): } \\
\hline $\begin{array}{l}1948-2000 \\
\text { Not available }\end{array}$ & 0.0086 & -0.0060 & 0.0230 & -0.0291 \\
\hline \multicolumn{5}{|l|}{ Auburn (NI): } \\
\hline $1893-2000$ & 0.0038 & -0.0002 & 0.0090 & -0.0092 \\
\hline 1900-1999 & 0.0060 & -0.0028 & 0.0144 & -0.0171 \\
\hline \multicolumn{5}{|l|}{ Valentine AP (NI): } \\
\hline $\begin{array}{l}1948-2000 \\
\text { Not available }\end{array}$ & -0.0005 & 0.0151 & -0.0160 & 0.0310 \\
\hline \multicolumn{4}{|l|}{ Pawnee City (NI): } & \\
\hline 1903-1999 & 0.0124 & 0.0090 & 0.0163 & -0.0073 \\
\hline
\end{tabular}

observed data-based findings. All irrigated locations indicate a decreasing trend in mean maximum temperature. In addition, four of these locations show an increasing trend in mean minimum temperature and decreasing trend in mean temperature. Hence, results from re-sampled data agreed with results from the original time series.

On the other hand, three non-irrigated locations including Auburn, Chadron, and Pawnee City show statistically significant (95\%) increasing mean minimum temperature. Analyses of DTR suggest statistically significant decreasing trend at these three nonirrigated locations (Pawnee City has 90\% confidence level). Hence, response of DTR from re-sampled data at non-irrigated locations also agrees with results from the observed data (see Mahmood et al., 2004). It is also found that in most cases mean and mean maximum temperature was increasing for non-irrigated 
Table 4

List of AWDN station locations and associated land uses for pairwise comparison

\begin{tabular}{lll}
\hline Location & Land use & Length of time series \\
\hline Alliance North & Irrigated & $06 / 01 / 88-12 / 31 / 03$ \\
Champion & Irrigated & $06 / 01 / 81-12 / 31 / 03$ \\
Clay Center & Irrigated & $08 / 01 / 82-12 / 31 / 03$ \\
Elgin & Irrigated & $01 / 01 / 88-12 / 31 / 03$ \\
Holdrege & Irrigated & $06 / 01 / 88-12 / 31 / 03$ \\
Holdrege $4 \mathrm{n}$ & Irrigated & $07 / 01 / 95-12 / 31 / 03$ \\
Kearney & Irrigated & $01 / 01 / 94-12 / 31 / 03$ \\
Minden & Irrigated & $07 / 01 / 95-12 / 31 / 03$ \\
North Platte & Irrigated & $01 / 01 / 83-12 / 31 / 03$ \\
Shelton & Irrigated & $01 / 01 / 91-12 / 31 / 03$ \\
West Point & Irrigated & $06 / 01 / 82-12 / 31 / 03$ \\
York & Irrigated & $05 / 01 / 96-12 / 31 / 03$ \\
Arapahoeprairie & Non-irrigated & $02 / 02 / 87-12 / 31 / 03$ \\
Arthur & Non-irrigated & $08 / 18 / 82-12 / 31 / 03$ \\
Gudmundsens & Non-irrigated & $10 / 08 / 82-12 / 31 / 03$ \\
Lincolnianr & Non-irrigated & $09 / 01 / 86-12 / 31 / 03$ \\
Halsey & Non-irrigated & $09 / 01 / 93-12 / 31 / 03$ \\
\hline
\end{tabular}

locations and thus agrees with results from original time series.

It is apparent that irrigated locations primarily exhibit lower daily mean maximum and mean temperature while non-irrigated locations indicate increasing daily mean maximum and mean temperatures. This study suggests that lowering of mean temperatures at irrigated locations are primarily forced by lowering of daily mean maximum temperatures while increasing mean temperatures at dry locations are primarily a function of increasing daily mean maximum temperatures at these areas. Land use change and increase of latent energy flux at irrigated locations are responsible for lowering of daily mean maximum temperatures. On the other hand, increasing daily mean maximum temperature at nonirrigated locations is in phase with increasing global temperatures.

This study suggests that increase in latent energy flux due to irrigation and subsequent modification of energy partitioning results in decreasing DTR. For example, a comparison of pre- and post- $1950 \mathrm{HCN}$ data sets for York and Alliance (irrigated location) shows a decrease in DTR. Also, Auburn and Pawnee City (both are non-irrigated locations), indicate a decrease in DTR. Thus, DTR has decreased under both irrigated and non-irrigated locations. In this study, the DTR decrease over irrigated locations occurred primarily due to the decrease in mean maximum temperature and increase in mean minimum temperature. Reductions of DTR over non-irrigated locations are largely related to increase in mean minimum temperature. Hence, there are increases of growing season mean minimum temperature under both land uses.

\subsection{Pairwise comparison of dew point temperature data from irrigated and non-irrigated locations}

These comparisons were completed for five nonirrigated and 12 irrigated locations (60 pairs total) (Table 4). For all locations, the AWDN programs calculated dew point temperature from RH data. Saturation vapor pressure (es) was obtained from Teten's (Murray, 1967) method; the actual vapor pressure (ea) was obtained from this relation: $[\mathrm{RH}=$ (ea/es)*100]. Subsequently, $T_{\mathrm{d}}$ was calculated from the method presented by Allen et al. (1994). Daily $T_{\mathrm{d}}$ was calculated as the average of hourly $T_{\mathrm{d}}$ estimates. The RH207 and Vaisala (both Campbell Scientific, Inc., 815 West 1800 North, Logan, Utah 84321-1784) probes were used before and after 1991, respectively.

Irrigated locations recorded notably higher dew point temperatures and underwent rapid rise compared to non-irrigated locations during the growing season months. For example, mean growing season dew point temperature at York (I) was $4.73{ }^{\circ} \mathrm{C}$ higher than Arthur (NI). Moreover, mean August dew point temperature was $5.43{ }^{\circ} \mathrm{C}$ higher at York (Fig. 14). Similarly, mean growing season dew point temperature for Shelton (I) was $3.97{ }^{\circ} \mathrm{C}$ higher compared to Arapahoeprarie (NI) and July dew point temperature was $4.58{ }^{\circ} \mathrm{C}$ higher. Comparison between naturally more moist eastern non-irrigated locations and irrigated western locations also demonstrates increasing moistness in the irrigated sites during the growing

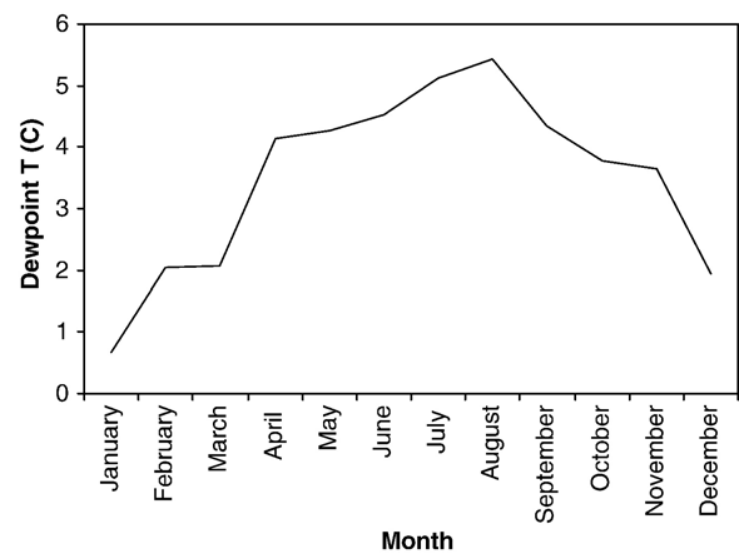

Fig. 14. Difference between mean monthly dew point temperatures at irrigated York and non-irrigated Arthur. 


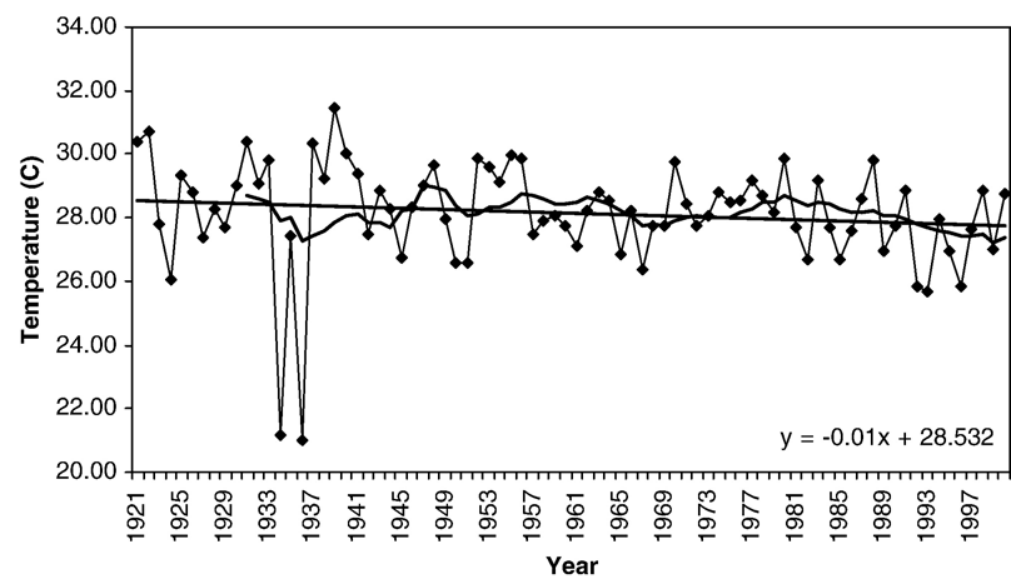

Fig. 15. Long-term growing season mean maximum temperature trend in York, Nebraska. (Source: Mahmood et al., 2004).

season. The results clearly show that land use change significantly modified near surface atmospheric moisture distribution and thus temperatures.

\section{Discussion}

Trend analyses of temperatures in the past showed a decreasing trend in growing season mean temperature and mean maximum temperature for these same locations (Mahmood et al., 2004). It was found that, for example, at York, both growing season mean and mean maximum temperature decrease at the rate of $-0.01{ }^{\circ} \mathrm{C} \mathrm{yr}^{-1}$ (Fig. 15). On the other hand, an increasing trend for the growing season mean temperature for all non-irrigated locations except for Valentine AP was observed. For example, growing season mean and mean maximum temperature increased at the rate of +0.005 and $+0.01{ }^{\circ} \mathrm{C}$ $\mathrm{yr}^{-1}$, respectively, at Halsey (Fig. 16). Pawnee City, a non-irrigated location, recorded $\mathrm{a}+0.01{ }^{\circ} \mathrm{C} \mathrm{yr}^{-1}$ increase in mean temperature for growing season.

Analyses of data from individual months suggest July and August experience the greatest rate of decrease in mean maximum temperatures for all irrigated locations (Mahmood et al., 2004). Mean temperature assessment produced similar results. In the study area, plants experience maximum physiological activities and growth during July and August. As a result, farmers apply a greater amount of irrigation during this period to meet plant-water demand. The availability of water and the elevated thermal and radiative condition in July and August provide a suitable environment for a higher evapotranspiration rate. It was suggested that this amplified modification of moisture and energy balance resulted in a greater rate of reduction of mean maximum

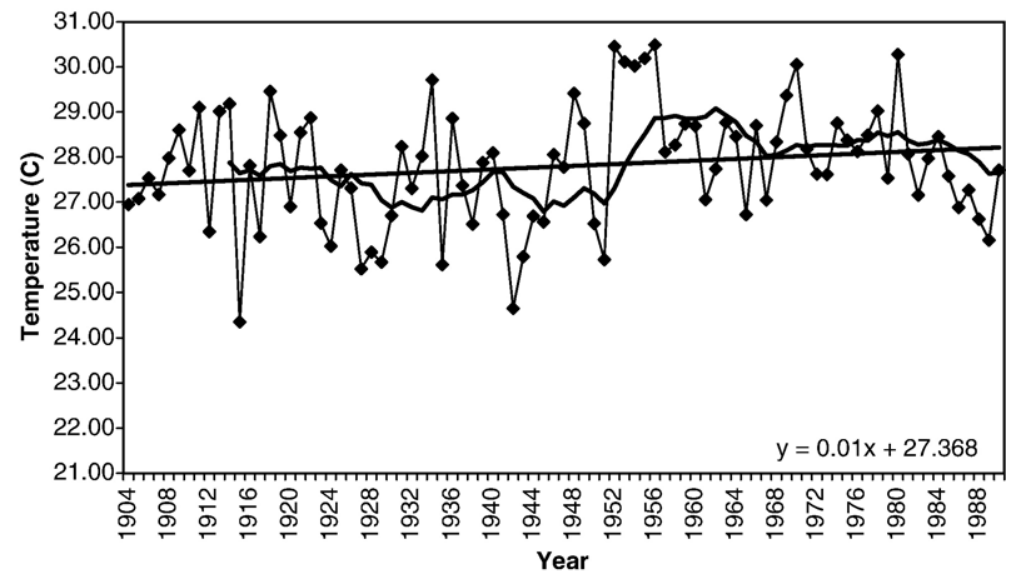

Fig. 16. Long-term growing season mean maximum temperature trend in Halsey, Nebraska. (Source: Mahmood et al., 2004). 
temperatures for irrigated locations during July and August (Mahmood et al., 2004).

Decreasing trends in extremely high temperatures were recorded at York, Osmond, Oakdale, and Box Butte. The greatest rate of temperature decrease is observed in July and August. Again, Mahmood et al. (2004) suggested that greater plant-water demand during these months and irrigated supply altered near surface energy balance and atmospheric moisture status. This subsequently resulted in modified extreme temperature records. In other words, land use change modified long-term temperature at these locations.

Kalnay and Cai (2003) have analyzed observed and NCEP/NCAR re-analysis data for 1950-1999 time period and found a cooling trend in maximum temperature during spring, summer, and fall in the Midwest. Moreover, they have reported strong positive and negative trend in minimum temperature and DTR for most of the US, respectively. They have attributed some of these results to land uses changes. Kalnay and Cai (2003) suggested that agricultural expansion would increase daytime evaporation and result in decreasing maximum temperature. Although their study did not explicitly differentiate between irrigated and nonirrigated land uses, as noted above, Kalnay and Cai (2003) argued that irrigation would increase heat capacity of the soil and hence the minimum temperature. Thus, it is possible to deduce that the combined impact of decreasing maximum temperature and increasing minimum temperature over the irrigated areas resulted in decreasing DTR. Their conclusions also explain the causes of increasing mean minimum growing season temperature at irrigated locations found in this study.

Christy and Norris (2004) investigated the impacts of irrigation in central California using COOP data from 1930 through 2000 for June, July, and August. They have reported a slightly negative trend in maximum temperature and a strongly positive trend in minimum temperature in the irrigated central valley of California. Like Kalnay and Cai (2003), this study suggests that the moist land surface releases previously absorbed energy during nighttime causing an increase in minimum temperature. Christy and Norris (2004) suggested increased evaporation resulted in lowering of maximum temperature. Therefore, the trend analyses by Kalnay and Cai (2003) and Christy and Norris (2004) agree with the findings of Mahmood et al. (2004) and the results of this study.

Global change studies suggest decrease in DTR as a result of increase in mean minimum temperature (e. g., Karl et al., 1993). It is found that DTR is sensitive to land use change within $10 \mathrm{~km}$ radius of an observing location (Gallo et al., 1996). In a follow up study by Gallo et al. (1999) found that DTR has decreased over the U. S. during the period of 1950-1996. Land use type did not make any difference in overall outcome of their study. It can be, hence, suggested that findings of our study agree well with the above studies. The authors of this study propose that two different controlling mechanisms are in place for increasing mean minimum temperatures under irrigated and non-irrigated conditions. In addition, we highlight the presence of complex land-atmosphere interactions and recommend an additional modeling study to better understand the forcing factors and mechanisms.

An assessment of the impacts of land use change on temperature of the Midwest and the Northeast suggests that the decrease in DTR resulted from greater cooling of daily maximum temperature compared to daily minimum temperature (Bonan, 1999). Note that his study did not differentiate between non-irrigated and irrigated land uses and did not include Nebraska and other major irrigated areas of the Great Plains. The pairwise analyses of COOP and HCN data in the present study indicate that, in most cases, both mean maximum and mean minimum temperatures over irrigated locations have cooled further during the second-half of the 20th century. Furthermore, the magnitude of cooling was also greater during this time period. However, cooling of mean maximum temperatures has been greater compared to mean minimum temperature. Thus, the result from this study agrees with Bonan's (1999) conclusion.

In the past, Mahmood and Hubbard (2002) and Adegoke et al. (2003) calculated up to $36 \%$ rise in ET and atmospheric moisture content over irrigated areas, respectively. In another model-based study, Bonan (1997) suggested a cooling of daily maximum temperatures and decrease in DTR over major agricultural areas of the United States. Hence, we conclude that the decrease in growing season daytime maxima occurred in response to the higher ET and associated evaporative cooling.

In another study, it is found that SM and precipitation together reduced DTR by 25-50\% (Dai et al., 1999). Evaporation of SM and subsequent cooling played the key role in this reduction of DTR (Dai et al., 1999). With the availability of moisture, energy partitioning is dominated by latent energy flux. This lowers both daily maximum temperature and DTR. The authors of this study argue that land use change due to introduction of irrigation and resultant increase in root zone SM enhanced evaporative cooling and lowered growing season mean maximum temperatures. It is found that SM is negatively correlated and an important modulator 
of DTR (Dai et al., 1999). Therefore, as near surface SM increases, it restricts the rise of maximum temperature by evaporation and subsequent cooling.

Recently, Durre and Wallace (2001) suggested that summertime dipping of DTR is related to growing season. Robinson et al. (1995) and Leathers et al. (1998) demonstrated large-scale changes in DTR are associated with seasonal progression. It is suggested earlier in this paper that the decreases in daytime mean maximum temperature and DTR in irrigated locations are related to greater evapotranspiration and a larger amount of energy partitioning to latent heat. A number of studies by Schwartz (1992, 1996) and Schwartz and Karl (1990) have found first leaf appearance is followed by an increase in atmospheric water vapor. These studies concluded that the increase in ET leads to higher atmospheric water vapor content and resultant decrease in both daytime warming and DTR.

Fitzjarrald et al. (2001) found that mean temperature was reduced at the time of spring season leaf emergence in the eastern United States. They attributed this reduction to partitioning of most of the net radiation into latent energy. Hence, during the period of maximum vegetation growth the daily maximum and mean temperatures become moderated due to changes in energy partitioning. Thus, with introduction of irrigation near surface thermal condition would also be cooled.

Mahmood et al. (2004) found, compared to other months, a larger decreasing rate for daily mean maximum temperature during July and August over the irrigated locations. A DTR minimum during July and August is also observed by Leathers et al. (1998) and Durre and Wallace (2001; Fig. 2). The high rate of ET during this period resulted in suppression of daily maximum temperature and subsequent minima. This condition reverses when plants approach senescence (Durre and Wallace, 2001). The present study suggests similar mechanisms have played a role in decreasing DTR over irrigated areas during the growing season.

\section{Summary and conclusions}

This paper investigated impacts of land use change and irrigation on near surface temperature of the northern Great Plains (NGP) during the growing season. It is found that, for example, mean maximum growing season temperature at irrigated Oakdale was $2.18{ }^{\circ} \mathrm{C}$ colder compared to non-irrigated Pawnee City during pre-1945 years. Comparison of post-1945 data for these locations shows $2.64{ }^{\circ} \mathrm{C}$ cooler temperatures at Oakdale. Thus, there was a $0.46{ }^{\circ} \mathrm{C}$ cooling during post- 1945 period. A comparison between irrigated Alliance and non-irrigated Halsey found a $1.01{ }^{\circ} \mathrm{C}$ cooling at irrigated site during post-1945 years. Comparison of growing season mean temperature also found that irrigated locations were cooler and that the magnitude of cooling was greater during post-1945 years compared to pre1945s. Additional assessment also suggests that the second half of 20th century experienced greater cooling due to the introduction of irrigation.

Analyses of temperature data identified maximum land use changes have occurred during the late 1940s and early 1950s. Robust tests using a $20 \%$-trimmed mean approach with bootstrapped sampling distributions were applied to determine if outliers or extreme values in the data had any impact on the overall outcome of results. This study finds that exclusion of the outliers did not change the overall findings of the study and hence, provided more validity to the main finding that land use change has modified long-term near surface temperature records. The bootstrapping method was applied to further verify the impacts of irrigation on temperature. The results, again, agreed well with observed data-based findings. In addition, 60 sets of pairwise comparisons for dew point temperatures were completed for irrigated and non-irrigated locations. The results show mean growing season dew point temperatures were consistently higher at irrigated locations. For example, at irrigated York it was $4.73{ }^{\circ} \mathrm{C}$ higher compared to non-irrigated Arthur. This finding provides evidence of impacts of land use change on near surface dew point temperature and further supports the idea that these changes altered long-term near surface temperature through human-induced modification of water and energy budgets.

Therefore, we conclude that introduction of irrigation (i.e., land use change) and its widespread adoption has significantly altered local and regional growing season temperature. Application of irrigation significantly increased root zone soil moisture and latent energy flux at climate and meteorological time scales. Thus, less sensible energy is available for near surface warming. The analysis and results of this study further validate our earlier findings. We suspect that land use change and its impact on local and regional temperature can be found in other parts of the world. Thus, we agree with Cai et al. (2004) and Pielke et al. (2002) and suggest that importance of land use change and its impacts on long-term near surface temperature should be further emphasized within the climate change framework. Detailed land use modeling studies should be conducted to understand these changes. Atmospheric models should be explicitly coupled with dynamic land 
use models to further understand controlling mechanisms. All spatial and temporal scales should be considered in these research efforts. Moreover, additional impetus is needed to analyze historical data within the broader context of land use change assessment and management.

\section{Acknowledgements}

The authors would like to thank three anonymous reviewers for their valuable comments which helped to improve this paper. Thanks also go to Daniel Taylor for preparation of Fig. 3.

\section{References}

Adegoke, J.O., Pielke Sr., R.A., Eastman, J., Mahmood, R., Hubbard, K.G., 2003. A regional atmospheric model study of the impact of irrigation on midsummer surface energy budget in the U. S. High Plains. Mon. Weather Rev. 131, 556-564.

Allen, R.G., Smith, M., Pereira, L.S., Perrier, A., 1994. An update for the calculation of reference evapotranspiration. ICID Bull. 43, $35-92$.

Balling Jr., R.C., 1988. The climatic impacts of a sonoran vegetation discontinuity. Clim. Change 13, 99-109.

Balling Jr., R.C., Klopatek, J.M., Hilderbrandt, M.L., Moritz, C.K., Watts, C.J., 1998. Impacts of land degradation on historical temperature records from the sonoran desert. Clim. Change 40, 669-681.

Betts, R.A., 2001. Biogeophysical impacts of land use on present-day climate: near-surface temperature change and radiative forcing. Atmos. Sci. Lett. 2, 39-51.

Bonan, G., 1997. Effects of land use on the climate of the United States. Clim. Change 37, 449-486.

Bonan, G., 1999. Observational evidence for reduction of daily maximum temperature by croplands in the Midwest United States. J. Climate 14, 2430-2442.

Bounoua, L., Collatz, G.J., Los, S.O., Sellers, P.J., Dazlich, D.A., Tucker, C.J., Randall, D.A., 2000. Sensitivity of climate to changes in NDVI. J. Climate 13, 2277-2292.

Bounoua, L., Defries, R., Collatz, G.J., Sellers, P., Khan, H., 2002. Effects of land cover conversion on surface climate. Clim. Change $52,29-64$.

Cai, M., Li, H., Kalnay, E., 2004. Impact of land use change and urbanization on climate. Proceedings of 14th Conference of Applied Climatology, Seattle, WA. www.ametsoc.org.

Chang, F.-C., Wallace, J.M., 1987. Meteorological conditions during heat waves and droughts in United States Great Plains. Mon. Weather Rev. 115, 1253-1269.

Chase, T.N., Kittel, T.G.F., Baron, J.S., Stohlgren, T.J., 1999. Potential impacts on Colorado Rocky mountain weather due to land use changes on the adjacent Great Plains. J. Geophys. Res. 104, 16, 673-16, 690.

Chase, T.N., Pielke Sr., R.A., Kittel, T.G.F., Nemani, R.R., Running, S. W., 2000. Simulated impacts of historical land cover changes on global climate in Northern Winter. Clim. Dyn. 16, 93-105.

Christy, J.R., Norris, W.B., 2004. Irrigation-induced warming in central California. Proceedings of 14th Conference of Applied Climatology, Seattle, WA. www.ametsoc.org.
Dai, A., Trenberth, K.E., Karl, T.R., 1999. Effects of clouds, soil moisture, precipitation and water vapor on diurnal temperature range. J. Climate 12, 2451-2473.

Durre, I., Wallace, J.M., 2001. The warm season dip in diurnal temperature range over the eastern United States. J. Climate 14, $354-360$.

Durre, I., Wallace, J.M., Lattenmaier, D.P., 2000. Dependence of extreme daily maximum temperatures on antecedent soil moisture in the contiguous United States during summer. J. Climate 13, 2641-2651.

Eastman, J.L., Coughenour, M.B., Pielke Sr., R.A., 2001. The regional effects of $\mathrm{CO} 2$ and landscape change using a coupled plant and meteorological model. Global Change Biol. 7, 797-815.

Fitzjarrald, D.R., Acevedo, O.C., Moore, K., 2001. Climatic consequences of leaf presence in the eastern United States. J. Climate 14, 598-614.

Gallo, K.P., Easterling, D.R., Peterson, T.C., 1996. The influence of land use/land cover on climatological values of the diurnal temperature ranges. J. Climate 9, 2941-2944.

Gallo, K.P., Owen, T.P., Easterling, D.R., 1999. Temperature trends of the U. S. Historical Climatology network based on satellitedesignated land use/land cover. J. Climate 12, 1344-1348.

Hansen, J.E., Sato, M., Lacis, A., Ruedy, R., Tegen, I., Matthews, E., 1998. Climate forcings in the Industrial era. Proc. Natl. Acad. Sci. USA 95, 12753-12758.

Hoffman, W.A., Jackson, R.B., 2000. Vegetation-climate feedbacks in the conversion of tropical savannas to grassland. J. Climate 13, 1593-1602.

Hogg, E.H., Price, D.T., Black, T.A., 2000. Postulated feedbacks of deciduous forest phenology on seasonal climate patterns in the western Canadian interior. J. Climate 13, 4229-4243.

Idso, S.B., Reginato, R.J., Reicosky, D.C., Hatfield, J.L., 1981. Determining soil-induced plant water potential depressions in Alfalfa by means of infrared thermometry. Agron. J. 73, 826-830.

Kalnay, E., Cai, M., 2003. Impact of urbanization and land use change. Nature 423, 528-531.

Karl, T.R., Jones, P.D., Knight, R.W., Kukla, G., Plummer, N., Razuvayev, V., Gallo, K.P., Lindseay, J., Charlson, R.J., 1993. A new perspective on recent global warming: asymmetric trends of daily maximum and minimum temperature. Bull. Am. Meteorol. Soc. 74, 1007-1023.

Leathers, D.J., Palecki, M.A., Robinson, D.A., Dewey, K.F., 1998. Climatology of the diurnal temperature range annual cycle in the United States. Clim. Res. 9, 197-211.

Mahmood, R., Hubbard, K.G., 2002. Anthropogenic land use change in the North American Tall Grass-Short grass transition and modification of near surface hydrologic cycle. Clim. Res. 21, 83-90.

Mahmood, R., Hubbard, K.G., 2003. Simulating sensitivity of soil moisture and evapotranspiration under heterogeneous soils and land uses. J. Hydrol. 280, 72-90.

Mahmood, R., Hubbard, K.G., 2004. An analysis of simulated longterm soil moisture data for three land uses under contrasting hydroclimatic conditions in the Northern Great Plains. J. Hydrometeorol. 5, 160-179.

Mahmood, R., Hubbard, K.G., Hou, Q., 2001. Soil moisture monitoring and modeling in the Great Plains. In: Hubbard, K.G., Sivakumar, M.V.K. (Eds.), Automated Weather Stations for Applications in Agriculture and Water Resources Management: Current Use and Future Perspectives, High Plains Climate Center, Lincoln, NE and World Meteorological Organization Geneva, Switzerland, pp. 163-171. 
Mahmood, R., Hubbard, K.G., Carlson, C., 2004. Modification of growing-season surface temperature records in the Northern Great Plains due to land use transformation: verification of modeling results and implications for global climate change. Int. J. Climatol. 24, 311-327.

Marland, G., Pielke Sr., R.A., Apps, M., Avissar, R., Betts, R.A., Davis, K.J., Frumhoff, P.C., Jackson, S.T., Joyce, L., Kauppi, P., Katzenberger, J., MacDicken, K.G., Neilson, R., Niles, J.O., Niyogi, D.D.S., Norby, R.J., Pena, N., Sampson, N., Xue, Y., 2003. The climatic impacts of land surface change and carbon management, and the implications for climate-change mitigation policy. Clim. Policy 3, 149-157.

Marshall, C.H., Pielke Sr., R.A., Steyaert, L.T., 2003. Crop freezes and land-use change in Florida. Nature 426, 29-30.

Marshall, C.H., Pielke Sr., R.A., Steyaert, L.T., Willard, D.A., 2004. The impact of anthropogenic land-cover change on the Florida Peninsula Sea Breezes and warm season sensible weather. Mon. Weather Rev. 132, 28-52.

McPherson, R.A., Stensrud, D.J., Crawford, K.C., 2004. The impact of Oklahoma's wheat belt on the mesoscale environment. Mon. Weather Rev. 132, 405-421.

Mooney, C.Z., Duval, R.D., 1993. Bootstarpping: A Nonparametric Approach to Statistical Inference. InSage Publications Newbury Park, California, p. 73.

Murray, F.W., 1967. On the computation of saturation vapor pressure. J. Appl. Meteorol. 6, 203-204.

Narisma, G.T., Pitman, A.J., Estman, J., Watterson, I.G., Pielke Sr., R., Beltran-Przekurat, A., 2003. The role of biospheric feedbacks in the simulations of the impact of historical land cover change on the Australian January Climate. Geophys. Res. Lett. 30, 2168. doi:10.1029/2003GL018261.

Pielke Sr., R.A., 2002. Overlooked issues in the U. S. National Climate and IPCC assessments: an editorial essay. Clim. Change 52, 1-11.

Pielke Sr., R.A., Marland, G., Betts, R.A., Chase, T.N., Eastman, J.L., Niles, J.O., Niyogi, D.D.S., Running, S.W., 2002. The influence of land-use change and landscape dynamics on the climate system: relevance to climate-change policy beyond the radiative effect of greenhouse gases. Philos. Trans. R. Soc. Lond., A 360, $1705-1719$.

Pitman, A.J., Narisma, G.T., Pielke Sr., R.A., Holbrook, N.J., 2004. Impact of land cover change on the climate of southwest Western Australia. J. Geophys. Res. 109, D18109. doi:10.1029/2003JD00437.
Ramankutty, N., Foley, J., 1999. Estimating historical changes in global land cover: Croplands from 1700 to 1992. Glob. Biogeochem. Cycles 13, 997-1027.

Robinson, J.M., Hubbard, K.G., 1990. Soil water assessment model for several crops in The high plains. Agron. J. 82, 1141-1148.

Robinson, D.A., Leathers, D.J., Palecki, M.A., Dewey, K.F., 1995. Some observations on climate variability as seen in daily temperature structure. Atmos. Res. 37, 19-31.

Roy, S.B., Hurtt, G.C., Weaver, C.P., Pacala, S.W., 2003. Impact of historical land cover change on the July climate of the United States. J. Geophys. Res. 108. doi:10.1029/2003JD003565.

Schwartz, M.D., 1992. Phenology and springtime surface-layer change. Mon. Weather Rev. 120, 2570-2578.

Schwartz, M.D., 1996. Examining the spring discontinuity in daily temperature ranges. J. Climate 9, 803-808.

Schwartz, M.D., Karl, T.R., 1990. Spring phenology: nature's experiment to detect the effect of green-up on surface maximum temperatures. Mon. Weather Rev. 118, 883-890.

Segal, M., Schreiber, W.E., Kallos, G., Garratt, G.R., Rodi, A., Weaver, J., Pielke, R.A., 1989. The impact of crop areas in northeastern Colorado on midsummer mesoscale thermal circulations. Mon. Weather Rev. 117, 809-825.

University of Nebraska-Lincoln (UNL), 2000. Center-pivot Irrigation Systems in Nebraska, 1997. UNL, Lincoln, NE.

Walsh, J.E., Jasperson, J.E., Ross, B., 1985. Influence of snow cover and soil moisture on monthly air temperature. Mon. Weather Rev. 113, 756-768.

Waisenan, P.J., Bliss, N.B., 2002. Changes in population and agricultural land in conterminous United States, 1790 to 1997. Glob. Biogeochem. Cycles 16, 1137. doi:10.1029/2001GB001843.

Wilcox, R.R., 1997. Introduction to Robust Estimation and Hypothesis Testing. Academic Press, San Diego.

Williams, K.R.S., 1992. Correlation between Palmer drought indices and various measures of air temperature in the climatic zones of the United States. Phys. Geogr. 13, 349-367.

Zhao, M., Pitman, A.J., 2002. The impact of land cover change and increasing carbon dioxide on the extreme and frequency of maximum temperature and convective precipitation. Geophys. Res. Lett. 29. doi:10.1029/2001GL013476. 